\title{
The development of a pulsating supraglacial stream
}

\author{
S. L. ST. GERMAIN, B. J. MOORMAN \\ Department of Geography, University of Calgary, Calgary, AB, Canada \\ E-mail: sstgerm@ucalgary.ca
}

\begin{abstract}
Supraglacial streams are a significant part of the glacial hydrological system and important for understanding the connection between glacial hydrology and glacier dynamics. Here we determine the factors that influence the development of step-pool formation and pulsating flow in a supraglacial stream on Bylot Island, Nunavut. Results show that during the second week of a 2-week study, multiple successive rainfall events occurred, stream temperature increased and ablation decreased; which also caused stream discharge to decrease. In addition, the stream, which flowed over a $13 \mathrm{~m}$ high waterfall off the front of Fountain Glacier, rapidly formed 21 step-pools and began to pulsate. The pulsating phenomenon involved the complete stoppage of flow over the waterfall and the subsequent restart between 8 and $20 \mathrm{~s}$ later. Pulsating flow resulted from rapid changes in the streambed morphology. In particular, the formation of the step-pool sequence was caused by helical flow around meander bends and hydrologically induced slippage along transverse shear planes, evidenced by observations of high-pressure artesian flow from transverse fractures. Contrary to previous literature, this study shows that high discharge is not necessarily the cause of step-pool formation and pulsating flow within supraglacial streams.
\end{abstract}

KEYWORDS: Supraglacial stream, pulsating, step-pools, rainfall

\section{INTRODUCTION}

Supraglacial streams are a significant part of glacial hydrology (Karlstrom and others, 2013), as they control spatial and temporal patterns of surface - derived meltwater to the englacial drainage system. Deeply incised supraglacial streams can form cut-and-closure conduits (Gulley and others, 2009), which can allow water to access the base of glaciers and ice sheets through efficient englacial flowpaths. Meltwater that reaches the basal region increases lubrication of the glacier bed and can facilitate periods of accelerated flow (Sole and others, 2013).

While there have been a number of fundamental studies on supraglacial streams (Knighton, 1972, 1981; Ferguson, 1973; Dozier, 1974, 1976; Marston, 1983), very little recent research has been done on supraglacial stream morphological dynamics at the ground-based level. There have been very few studies on supraglacial streams in Canada and Greenland. Two exceptions include the broad characterization of the supraglacial hydrologic network (Lampkin and Vanderberg, 2014) and the characterization of supraglacial water storage, drainage pattern and discharge (Smith and others, 2015); both of which use satellite imagery. In addition to studies using satellite imagery, there has been a renewed interest in numerical modeling of supraglacial channels (Jarosch and Gudmundsson, 2012; Karlstrom and others, 2013, 2014).

Channel pattern and geometry are significant aspects as they determine channel resistance and control water velocity (Vatne and Refsnes, 2003). Step-pools are a channel pattern that have been observed in alluvium, bedrock and supraglacial streams, and are considered a fundamental element of fluvial environments (Knighton, 1998). A step-pool sequence has a stair-like appearance; where a pool is eroded directly underneath a step, and a promontory (or lip) forms directly downstream from the pool (Fig. 1). The lip forms a reverse bed slope within the stream profile, and thus forces water to travel against gravity to travel farther downstream (Vatne and Refsnes, 2003). Although these formations occur in a number of environments, the mechanics controlling their formation are quite different. Step-pools in alluvial rivers develop during extreme floods. Vatne and Refsnes (2003) assumed that step-pools also form in glacial meltwater streams during high discharge. However, they attributed their formation to the added energy, in the form of heat from frictional dissipation. A handful of studies have been undertaken on step-pool formation within englacial flowpaths, however they have rarely been investigated in supraglacial streams on polythermal glaciers (Irvine-Fynn and others, 2011).

Pulsating flow has only been noted in the literature on a few occasions (Knighton, 1981; Carver and others, 1994; Van der Meer, 2004) and influences the velocity and discharge within supraglacial streams. Pulsating involves the complete stoppage (or extreme sudden reduction) of discharge and the subsequent restart of flow. As the occurrence of pulsating flow is rare and sporadic in nature, it is challenging to study this unusual phenomenon. To date, the literature has focused on characterizing flow pattern, but fails to explain the underlying mechanisms leading to the pulsating and the processes involved in this phenomenon. Here we determine factors that influence the development of a small supraglacial stream, specifically in relation to rapid changes in streambed morphology and the processes that cause pulsating flow to occur.

\section{STUDY AREA}

Bylot Island is a small heavily glacierized island located in the Canadian Arctic Archipelago at latitudes of $72.5^{\circ}$ and 


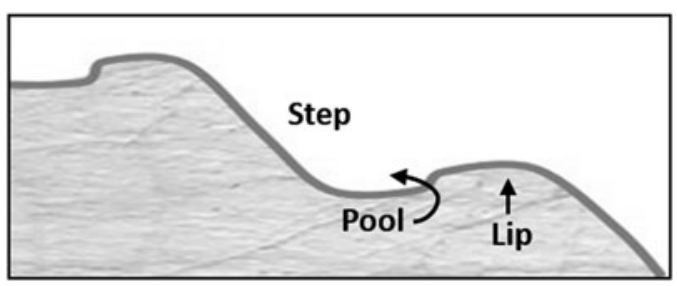

Fig. 1. Schematic cross section through a step-pool streambed.

$74^{\circ} \mathrm{N}$, and longitudes of $76^{\circ}$ and $81^{\circ} \mathrm{W}$. Fountain Glacier, located on the southern side of Bylot Island, is $\sim 16 \mathrm{~km}$ long, with a catchment area of $72 \mathrm{~km}^{2}$ (Fig. 2a) (Wainstein and others, 2014). Fountain Glacier is thought to be polythermal in nature, having a temperate ice core covered by a layer of cold ice (Moorman and Michel, 2000). Over the past two decades, the terminus of Fountain Glacier has undergone major changes. In the early and mid-1990s, it terminated as

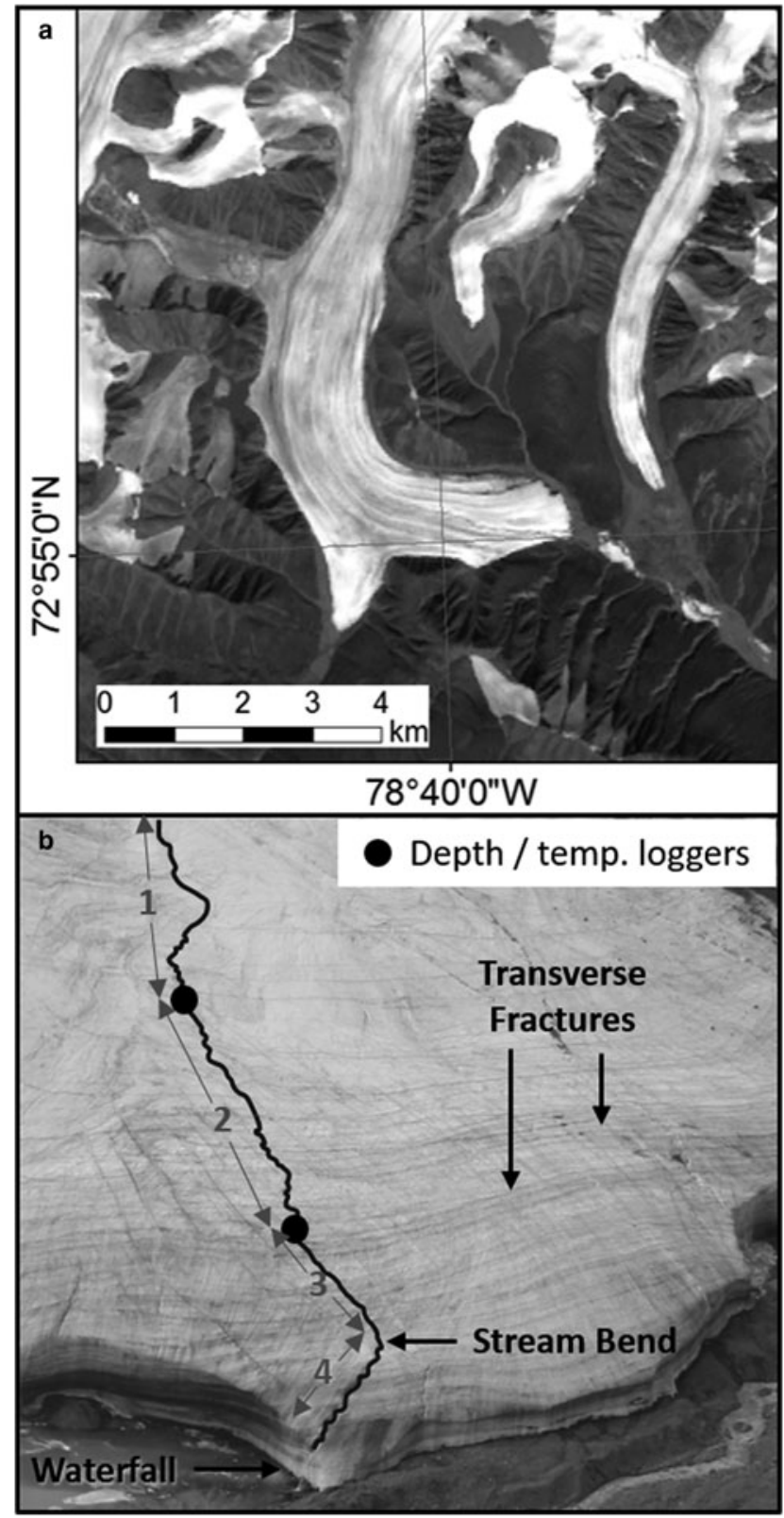

Fig. 2. (a) Fountain Glacier study area located on Bylot Island and (b) the studied supraglacial stream located near the terminus of Fountain Glacier. Arrows denote the 4 reaches. Key structural elements and stream characteristics are also shown. a gentle slope that was walkable. Most of the glacier now terminates in a cliff face up to $20 \mathrm{~m}$ in height due to a number of dry calving events (Whitehead and others, 2013).

Research was conducted on one of the small supraglacial streams located in the center of Fountain Glacier. This stream flows off the front of the glacier in the form of a $13 \mathrm{~m}$ high waterfall (Fig. 2b). The lower $1.5 \mathrm{~km}$ of Fountain Glacier (within the catchment) is a zone of compressive flow (Whitehead and others, 2013), and dominated by steeply dipping transverse fractures, which are parallel to the terminus (Fig. 2b). The majority of the glacier terminus is composed of coarse bubbly ice, while the transverse fractures are made up of coarse clear ice.

The studied stream is $1.2 \mathrm{~km}$ in length, with an average depth of $8 \mathrm{~cm}$, and width of $40 \mathrm{~cm}$. Along the length of the stream the width and depth varies considerably; however, in general it increases in size towards the terminus. Significant changes in sinuosity and slope also occur within the catchment. For this reason, the stream was divided into four reaches; Reach 1 above the top depth logger, Reach 2 bounded by the two loggers, Reach 3 between the bottom logger and the stream bend and Reach 4 between the stream bend and waterfall (Fig. 2b).

\section{METHODS}

\section{Meteorological data}

A Campbell Scientific Automatic Weather Station located in the center of a glacier in an adjacent valley $4 \mathrm{~km}$ away from the study site) collected representative data including: air temperature, relative humidity and net radiation on an hourly basis for the duration of the study. Daily precipitation was estimated using a combination of sources; a precipitation pan on Fountain Glacier, local time-lapse imagery, and an Environment Canada weather station (located 35 $\mathrm{km}$ away in the Hamlet of Pond Inlet).

\section{Ablation}

A miniature ablation stake survey was completed within the watershed of Reach 2. For this survey, wooden dowels, $5 \mathrm{~mm}$ in diameter, were inserted into the same sized holes that were drilled into the glacier surface. A total of 25 stakes were installed throughout the watershed between 7 and 8 July and the average daily ablation over the study period was measured.

\section{Supraglacial stream discharge}

Stream discharge was measured using a combination of the velocity-area method and stage measurements. The velocity-area method is effective for determining discharge, but is labor intensive. To increase the temporal resolution of the discharge estimations, rating curves were developed so that discharge estimates could be made from stage measurements. The stage was recorded every minute from 8 to 21 July using two Model 3001 Solinst Levelogger pressure and temperature loggers (accuracy of $0.3 \mathrm{~cm}$ water depth and $\pm 0.05^{\circ} \mathrm{C}$ temp.). One was installed at the top of Reach 2 and the other at the bottom of Reach 2 (Fig. 2b). As the streambed is subject to differential melt over time, a hole was drilled into the center of the supraglacial streambed and the loggers were installed within the holes to provide a stable vertical reference point, similar to the method of 
Willis and others (2002). While taking the velocity-area measurements, the distance between the logger and streambed was measured to calculate streambed melt and used to correct the stage measurements. A Flowatch Meter $( \pm 2 \%)$ was used to measure velocity across the stream. Average water velocity was measured every $10 \mathrm{~cm}$, at $40 \%$ depth from the bed surface (assumed to be the representative depth for the averaged velocity). Measurements were taken 14 times over the course of the entire study period at different times of the day to ensure the range of discharges were captured (time measurements seen in Fig. 3c). From these series of measurements, a linear rating curve was calculated $\left(r^{2}=\right.$ $0.96)$ to provide the discharge estimates from the stage alone.

\section{Streambed profiles}

Streambed profiles were collected within Reach 2 using a Trimble Real Time Kinematic GPS (Karlstrom and others, 2013). Duplicate streambed profiles were measured a week apart to determine the changes in streambed morphology and to identify the location and size of pools and meander bends. The first survey was conducted on 13 July. The second streambed survey took $3 \mathrm{~d}$ to complete; parts of Reach 2 were surveyed on 22, 23 and 24 July. A large amount of overlap between the survey sections allowed for the three survey sections to be adjusted to all reflect the streambed elevation on 23 July. The average horizontal and vertical precision of the survey measurements were 0.8 and $1.5 \mathrm{~cm}$, respectively.

\section{Time-lapse and video imagery}

On 10 July, a Wingscapes WSCA04 outdoor time-lapse camera was positioned $450 \mathrm{~m}$ down valley from the glacier terminus to record the activity of the supraglacial stream, where the waterfall flows off the glacier. The camera was set to take images every $10 \mathrm{~min}$. The camera also captured the occurrence of the rainfall events. In addition to the
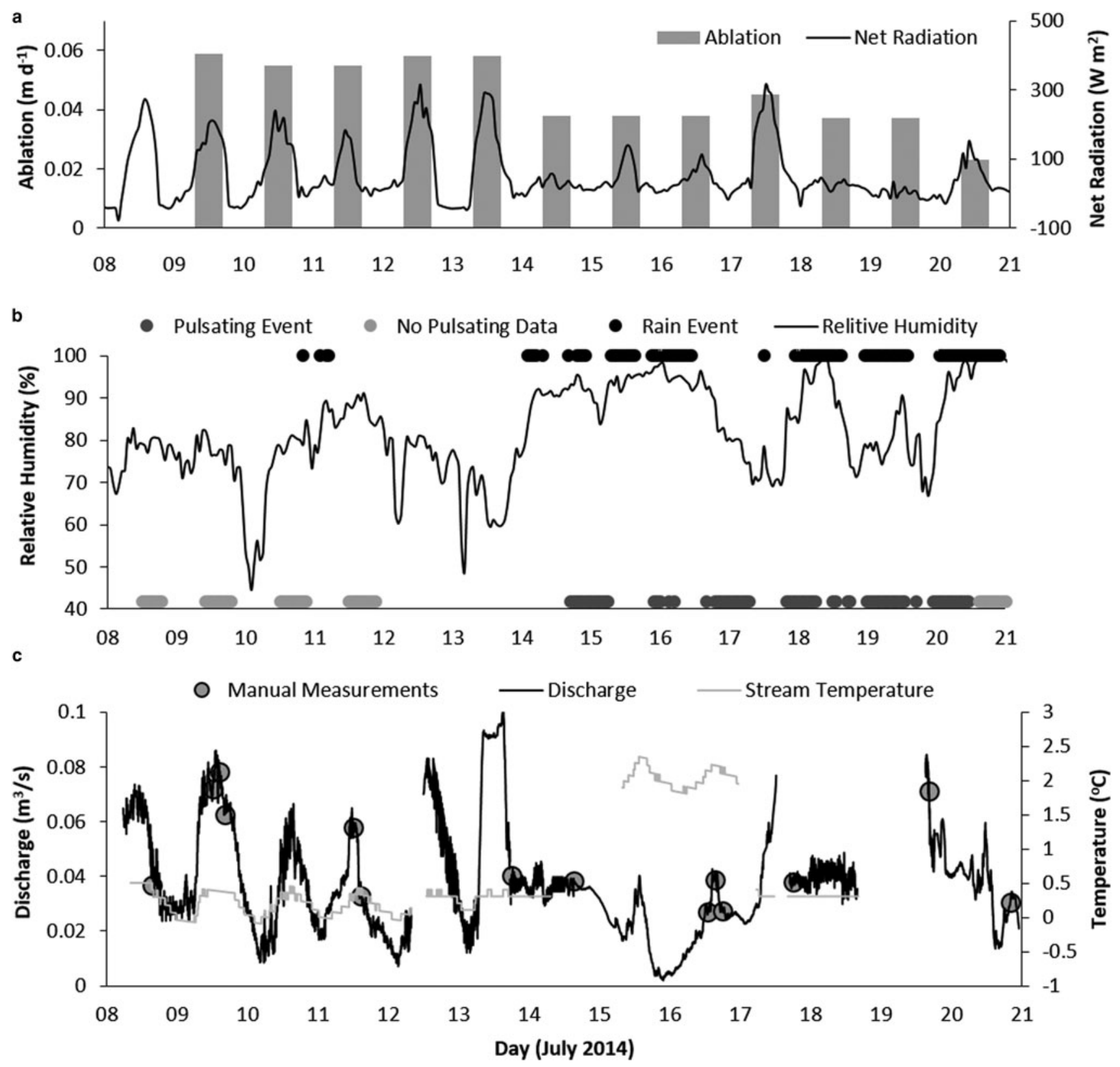

Fig. 3. (a) Shows fluctuations in ablation and net radiation, (b) shows relative humidity, rainfall and pulsating events, and (c) shows discharge and stream temperature from the top logger, as well as the time of the manual discharge measurements. 
Table 1. The sinuosity and slope values measured along the studied stream

\begin{tabular}{lcr}
\hline & Sinuosity & $\begin{array}{c}\text { Slope } \\
\%\end{array}$ \\
\hline Reach 1 & 1.04 & 8 \\
Reach 2 & 1.09 & 10 \\
Reach 2 - upper half & 1.08 & 9 \\
Reach 2 - lower half & 1.10 & 11 \\
Reach 3 & 1.05 & 20 \\
Reach 4 & 1.18 & 36 \\
\hline
\end{tabular}

time-lapse imagery, two $60 \mathrm{~s}$ videos were taken on 22 July to capture sudden changes in discharge.

\section{RESULTS}

\section{Hydrometeorology}

Many of the hydrometeorologic characteristics changed between the first and second week of the study. The net radiation fluctuated on a daily cycle, but significantly decreased during the second week (Fig. 3a). The ablation rate also changed drastically throughout the study period. From 913 July the average ablation was $0.057 \mathrm{~m} \mathrm{~d}^{-1}$, whereas from 14-22 July the average ablation was only $0.036 \mathrm{~m}$ $\mathrm{d}^{-1}$ (Fig. 3a). The average relative humidity was $82 \%$, with a minimum of $45 \%$ (Fig. 3b). Rain events occurred on 11 , 14-16 and 18-21 July (Fig. 3b), with a total of $26 \mathrm{~mm}$ of rain falling from 14-21 July.

The stream discharge and temperature measured from 8 to 21 July is shown in Figure 3c. Some of the data was corrupt and had to be omitted during certain periods due to the refreezing of the hole the loggers were installed in. The supraglacial stream discharge ranged between $10 \times 10^{-3}$ and $10 \times$ $10^{-1} \mathrm{~m}^{3} \mathrm{~s}^{-1}$ with an average uncertainty of $7 \times 10^{-4} \mathrm{~m}^{3} \mathrm{~s}^{-1}$ between the measured and estimated discharge. During 8-13 July, a daily cyclical pattern can be seen in the discharge; however, this pattern was much less obvious from 14-21 July. Stream temperature also varied on a daily cycle, ranging from 0.4 to $-0.3^{\circ} \mathrm{C}$ during the first week. This is similar to values found by Isenko and others, (2005). However, on 15 and 16 July the stream temperature increased to a maximum of $2.4^{\circ} \mathrm{C}$, and fluctuated $\sim 2^{\circ} \mathrm{C}$ for the next $2 \mathrm{~d}$.

The decrease in net radiation from cloudy conditions during the rainy periods was associated with a decrease in glacier surface melt and a consequent decrease in overall discharge during the second week. In addition, the combination of lower ice melt and the contribution of warmer rain water resulted in the stream temperatures also increasing during the second week.

\section{Stream channel characteristics}

Although the stream sinuosity was greater in the steeper sections near the terminus of the glacier (Table 1), the overall sinuosity of the stream was 1.07 and did not significantly change over the study period. The Reynolds number, calculated using manual stream discharge measurements at the top of Reach 2, ranged from $5.6 \times 10^{3}$ to $1.4 \times 10^{4}$, indicating very turbulent flow at all times (Anderson and McDonnell, 2005). The Froude number, calculated at the same location, was found to be above 2 throughout the study period, indicating continuous supercritical flow (Anderson and McDonnell, 2005).

There was a significant increase in the number of steppools between 13 and 22 July. The 13 July stream profile had a total of 5 step-pools, however there were a total of 26 step-pools from the 22-24 July profile (Fig. 4). On 13 July, the average pool depth was $7.5 \mathrm{~cm}$, while the step height was $39 \mathrm{~cm}$. The 22 July survey was taken of the upper half of Reach 2, and had an average pool depth of $8.2 \mathrm{~cm}$ and a step height of $17 \mathrm{~cm}$. The 23 July survey was taken along the lower half of Reach 2, and had an average pool depth of $8.9 \mathrm{~cm}$ and a step height of $30.2 \mathrm{~cm}$. The rapid development within the streambed (13-22 July) was associated with the change that occurred in the meteorological parameters, specifically the rainfall and increase in stream temperature that began at the same time as the steppool evolution.

On 16 July, at 15:00, it was noted that the waterfall was pulsating, where the discharge went from a maximum to zero, with a period of $\sim 17 \mathrm{~s}$. This led to further examination of discharge throughout the study period. Specifically, manual measurements of discharge were taken at the top logger location at 17:30 and at the bottom logger location

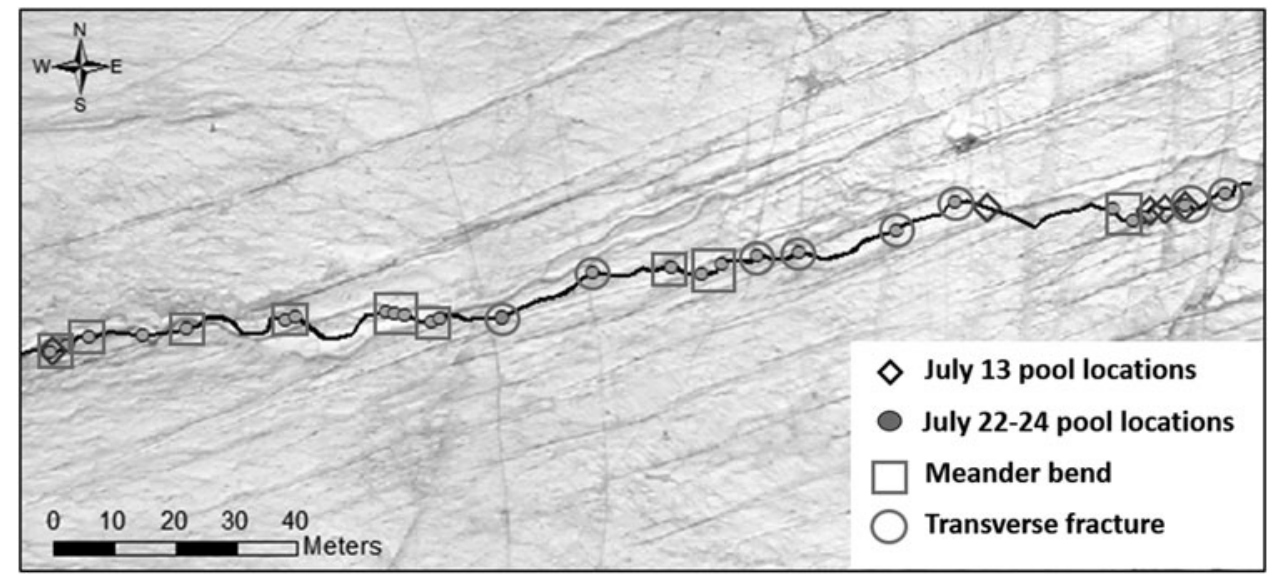

Fig. 4. Aerial view of Reach 2 showing the step-pool locations on 13 July and 22-24 July. Note that five step-pools existed in the streambed on 13 July and 26 step-pools were present on 22-24 July. The image also illustrates the pools and the connection with the stream meander bends and transverse fractures. 
at 17:48 over a $60 \mathrm{~s}$ duration. At the bottom logger location, the average was $5.2 \times 10^{-3} \mathrm{~m}^{3} \mathrm{~s}^{-1}$; with a maximum of $7.6 \times 10^{-2} \mathrm{~m}^{3} \mathrm{~s}^{-1}$, and a minimum of $5 \times 10^{-3} \mathrm{~m}^{3} \mathrm{~s}^{-1}$. The average discharge at the top logger location was $4.1 \times$ $10^{-2} \mathrm{~m}^{3} \mathrm{~s}^{-1}$, maximum of $4.8 \times 10^{-2} \mathrm{~m}^{3} \mathrm{~s}^{-1}$ and minimum of $3.6 \times 10^{-2} \mathrm{~m}^{3} \mathrm{~s}^{-1}$. Thus discharge was more variable in magnitude at the bottom than the top. At the bottom logger, the pulsating flow seemed to be occurring at a somewhat regular rate, with a sudden decrease occurring every $12-15 \mathrm{~s}$.

Later examination of the time-lapse photos from the base of the waterfall indicated that the pulsating had actually started on 14 July and continued until 22 July. On 22 July, discharge was examined at the bottom logger location, at the stream bend and at the base of the waterfall. The discharge recorded at the bottom logger location was taken at $10: 35$ by manually recording velocity for $60 \mathrm{~s}$. The discharge was extremely variable ranging between $7.7 \times 10^{-2}$ and $4.1 \times 10^{-2} \mathrm{~m}^{3} \mathrm{~s}^{-1}$, however no trend was seen. Five minutes after the measurements at the bottom logger, at 10:40, a video of the water was taken at the stream bend, which was $130 \mathrm{~m}$ farther downstream. Examination of the video shows that pulsating occurred at regular intervals in this location. During the $60 \mathrm{~s}$ video, four pulsating periods were observed. The discharge was high for 7-10 s, then suddenly dropped to zero for 8-15 s. At 11:20, another $60 \mathrm{~s}$ video was taken, this time at the waterfall (230 m downstream from the bottom logger). This video recorded only two pulsating periods. The discharge flowed for $\sim 18 \mathrm{~s}$ followed by $10-15+s$ of no flow. Clearly, the period between zero and high discharge became amplified with increasing distance downstream.

Figure $3 \mathrm{~b}$ shows that the pulsating events began in parallel to a significant increase in relative humidity and rainfall. Although the days containing rain events and pulsating flow were correlated, the exact timing of the pulsating and rainfall events were not. A comparison between Figures $3 \mathrm{~b}$ and $\mathrm{C}$ shows that pulsating events were more likely to occur during low discharge.

\section{DISCUSSION}

Step-pools in alluvial rivers develop during extreme floods, however discharge decreased during the formation of steppools in this supraglacial stream. As supraglacial streams have strongly diurnal discharge patterns (Marston, 1983), the environment is adapted to large and rapid changes in discharge. It is hypothesized that for step-pools to form in a supraglacial stream as a result of high discharge, rainfall amounts would have to far exceed the normal discharge fluctuations that occur. This did not occur in the studied stream.

Vatne and Refsnes (2003) assumed that step-pools also form in glacier meltwater streams during high discharge. This is because frictional heat is related to the volume of water in the stream (Knighton, 1972), so at high discharge, step-pools can form from the added energy of frictional heat. Our results show that discharge decreased during step-pools formation, but this does not preclude frictional heating as an important causal process in their formation.

Helical flow was observed in the stream throughout the study period and the calculated Reynolds numbers verify that flow conditions were always turbulent. Although overall discharge was significantly less during the second week of the study, high variability in discharge associated with the pulsating flow phenomenon ensured that at the very beginning of a pulse, helical flow occurred around meanders (Fig. 5a). The added thermal energy from increased stream temperatures is likely to have enabled pools to form rapidly (Fig. 5b).

Figure 4 shows an aerial view of the stream with the locations of the 26 pools that formed in Reach 2 during 13-24 July. Only $\sim 2 / 3$ of the pools are located immediately downstream of a meander. Dozier (1974) suggested that structural elements such as shear planes normal to the stream result in knickpoints or steps. Figure 4 does show a clear correlation between the remaining $1 / 3$ of the pools and some of the shear planes (or in this case transverse fractures). However, the structural elements (time independent) cannot explain the rapid development of the step-pools (time evolving).

We propose a second mechanism for step-pool formation in relation to the glacier structure and in connection with the multiple rainfall events. On 20 July sediment-laden water flowed from the transverse fractures on the north side of Fountain Glacier (Fig. 6) indicating a hydrological connection with the bed. This hydrological event continued on and off from 20-22 July. We suggest that rainfall led to the recharge of the subglacial hydrological system, causing the hydrostatic pressure within the glacier to increase. This

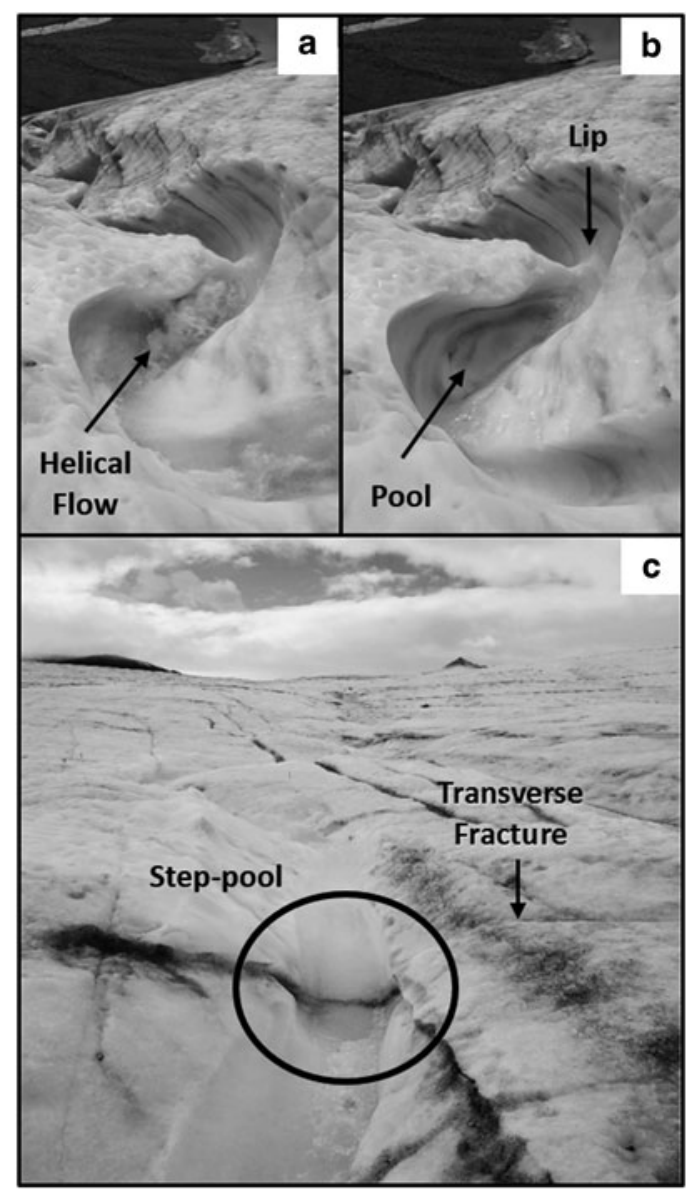

Fig. 5. Step-pool formation from helical flow; (a) shows the beginning of a pulse with helical flow occurring around the stream bend, and (b) shows the stream a few seconds later, in between pulses events. It can be seen where the helical flow created the pool and subsequent lip. Images A and B were taken on 22 July at $10: 40$ at the major stream bend (top of Reach 3). Photo credit: Michelle Blade. (c) Transverse fracture formed step-pool. Image was taken on 22 July within Reach 2. 


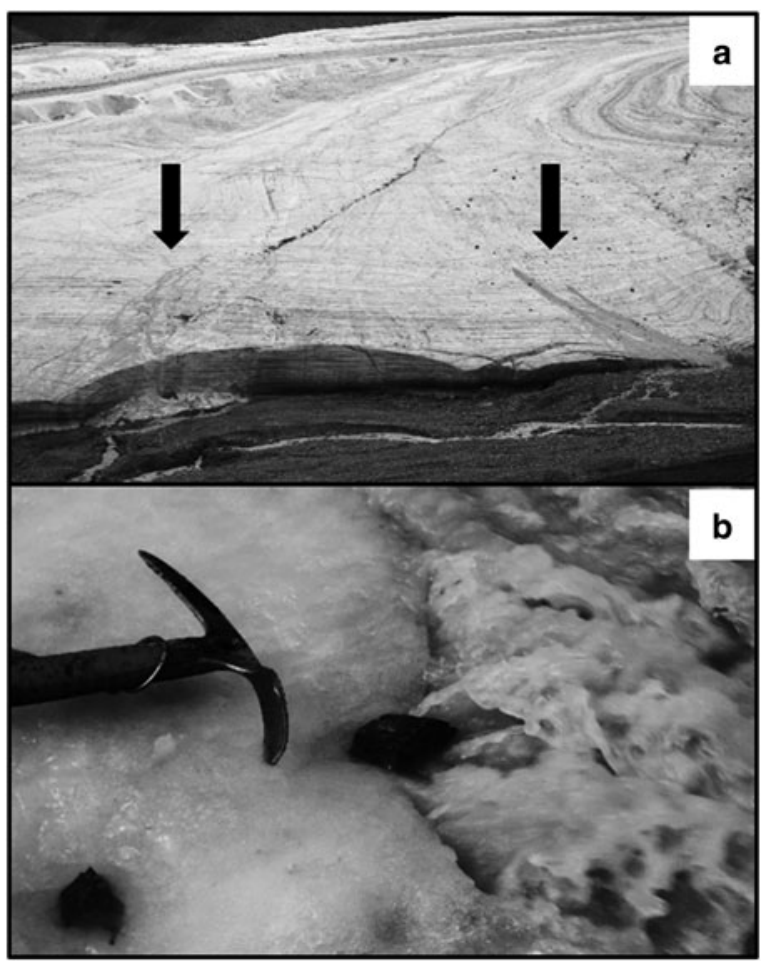

Fig. 6. Image of a hydrological event taken on 20 July; (a) shows the location of two springs (indicated by arrows), where sediment-laden water emerges from the surface of Fountain Glacier, and (b) shows close up image of the water flowing from a transverse fracture (Photo credit: Michael Hambrey).

resulted in artesian flow at the surface and lubrication of the shear plane fractures. The combination of the lubricated transverse fractures and compressive flow of the terminus may have caused slip events to occur along the fractures. It is also possible that in addition to the slip events, differential melt occurred along the transverse fractures due to the variation in ice crystal character (Hambrey, 1977). Whether from slip events, differential melt, or both, at the locations where the transverse fractures crossed the stream, a step formed, which in turn also created an erosional plunge pool (Fig. 5c).
As illustrated in the section Results, the pool-depth and step height increased between 22 and 23 July. The data suggests that the extra day of rainfall allowed for further pool development. It is also possible that helical flow was the cause of larger steps and deeper pools due to the more sinuous conditions in the lower half of Reach 2. In fact, both of these reasons likely explain the difference in step height and pool depth.

\section{Pulsating phenomena}

Channel character, specifically step-pools have the ability to change/create certain flow characteristics such as roll waves, travelling waves and then pulsating flow. Irrespective of the step-pool formation mechanism, where the channel 'steps' it is generally convex, narrower and shallower due to the laminar flow. At the inflection point between the convexity of the step and concavity of the pool, the flow immediately changes from supercritical to subcritical, causing the formation of a hydraulic jump (Knighton, 1981). As the water travels downstream into the pool, the flow returns to a supercritical/turbulent state. As changes in flow behavior occur within these sequences, there is also a local change in the Froude number with the value decreasing between the straight and meandering reaches.

Roll waves form in locations where flow is unstable due to very high velocity and/or very steep gradients. A breaking wave forms, when the wave velocity is greater than that of the surface flow adjacent to the channel bed and sides (Carver and others, 1994). Supraglacial channels are characterized by increased flow velocity largely due to the restraints of the cross-sectional area (Knighton, 1981). Roll waves are strongly three dimensional (3-D) in nature (Carver and others, 1994) and the smoothness of the liquid/solid interface in supraglacial streams allows for a free surface flow and facilitates water to travel in a 3-D oscillation (Camporeale and Ridolfi, 2012). The combination of rapid increase in velocity and the smooth liquid/solid interface of supraglacial streams results in a good environment for roll waves to form.

Carver and others (1994) suggest that in a supraglacial stream, a Froude number $>2$ would allow for the formation a

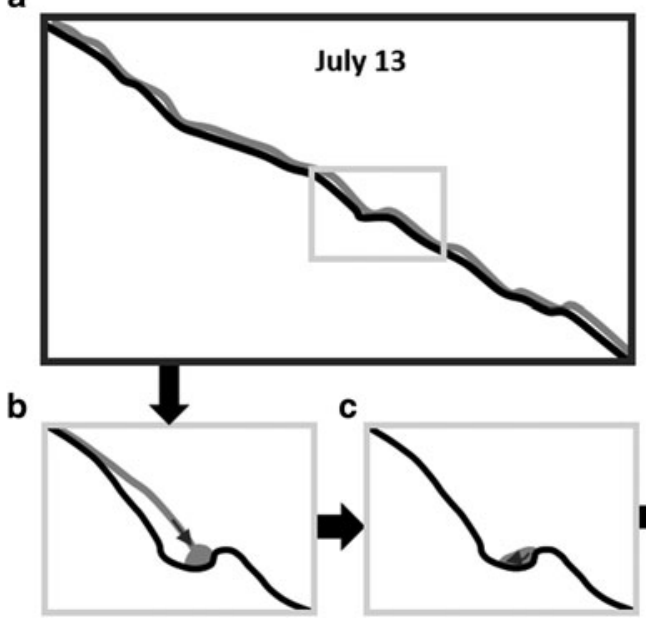

$\mathbf{f}$

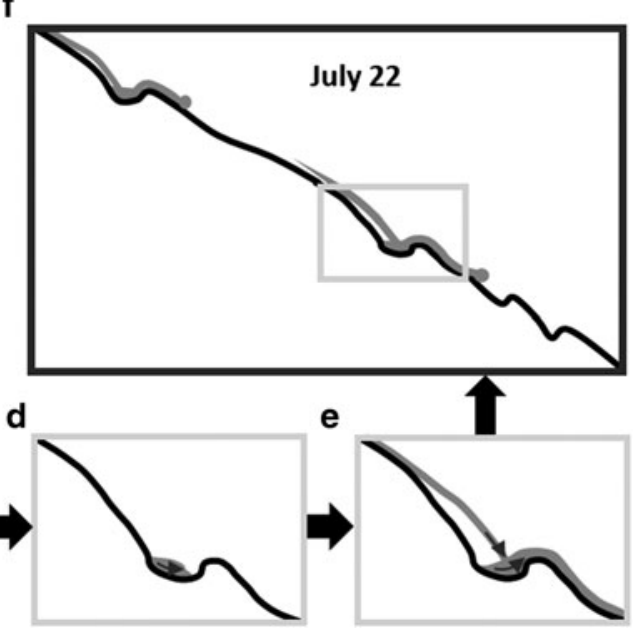

Fig. 7. A schematic representation (using a $30 \mathrm{~m}$ to scale profile of the streambed) to demonstrate how constructive interference leads to periods of pulsating; where (a) shows continuous flow conditions (b-d) illustrate how at certain discharge rates backflow within a pool temporarily retards the overall stream flow, (e) the impact of the constructive interference is rapidly changing discharge, and (f) shows the resultant travelling waves. 
of a roll wave. Results show that although discharge decreased during the second week of the study, the velocity was still high, and the Froude number was always $>2$. When instability occurs, the formation of a series of roll waves can break down into travelling waves or pulsating flow (Carver and others, 1994).

Figure 7 depicts the transformation of the streambed and change in flow patterns on 13 July (the day before the rain began), and 22 July (after it had been raining for a week). Figure $7 \mathrm{a}$ shows continuous flow conditions as no steppools existed within the channel. With the rapid formation of the step-pools, the flow pattern changed. Figures $7 \mathrm{~b}-\mathrm{d}$ illustrate how, at certain discharge rates, backflow within a pool temporarily retards the overall stream flow. Importantly, if the water was slushing forwards as another travelling wave entered the pool, a constructive interference pattern would occur (Fig. 7e). If this pattern was not achieved, it was destructive inference, and no pulsating occurred. As illustrated in Figure $7 f$, the travelling wave (or beginning of the pulse) had a turbulent rounded front with a smooth tail section. During the pulse, the discharge was extremely high, but between the pulses, the channel was either completely empty or discharge was very low. Once a pulse abated, the next wave would periodically arrive.

The pulsating phenomenon within supraglacial streams has only been noted in the literature on a few occasions (Knighton, 1981; Carver and others, 1994). Van der Meer (2004) documented a pulsating period of 8-12 s on Usherbreen Glacier, Svalbard. He noted that within the streambed, numerous transverse ribs caused the emergence of a sinusoidal wave that increased in amplitude farther downstream. Similarly our observations revealed a quasisinusoidal wave pattern from the amalgamation of the waves. As the pulsation traveled farther downstream, the pools acted as a temporary store, increasing the period between waves. As the local discharge and slope increased downstream, the amplitude of the wave also increased in size. Within a $60 \mathrm{~s}$ time frame and $100 \mathrm{~m}$ section, the amplitude and period had increased to the point that 1 less full pulsation cycle was observed downstream.

The exact development of the step-pools was not monitored regularly and as such the evolutionary timescale of the step-pools in connection to rainfall amounts is not fully understood. Nonetheless, the pulsating phenomenon may give some insight into the step-pool development. Pulsating often occurred between 22:00 and 5:00 from 14-17 July when discharge was low, but on 18, 19 and 22 July shorter erratic episodes were observed during the day. Since the discharge was higher during the day, it is likely that pulsating flow could only occur at this time once the pools were sufficiently deep.

\section{SUMMARY AND CONCLUSIONS}

During July 2014, the streambed morphology and flow characteristics of a supraglacial stream altered drastically. Unlike alluvial streams where discharge is the cause of the step-pool formation, discharge could not have been a factor as it was significantly less during the time of formation. These results suggest that previous studies may have overstated the role of high discharge in the formation of step-pool sequences within supraglacial streams. Short-term changes in streambed morphology appear to be related to helical flow around meanders and slippage along transverse shear fractures in response to high hydrostatic pressures within the glacier, probably caused by rainfall. In conclusion, changes in morphology and structure play an important role in the formation of pulsating flow.

\section{ACKNOWLEDGEMENTS}

This work was supported by the Natural Sciences and Engineering Research Council of Canada (NSERC) through a research grant held by Brian Moorman, Polar Continental Shelf Project (PCSP), Parks Canada, Northern Scientific Training Program (NSTP), Arctic Institute of North America (AINA) and University of Calgary.

\section{REFERENCES}

Anderson MG and McDonnell JJ (2005) Encyclopedia of hydrological sciences: volume 4. John Wiley \& Sons, Ltd, Etobicoke, Ontario

Camporeale C and Ridolfi L (2012) Ice ripple formation at large Reynolds numbers. J. Fluid Mech., 694, 225-251 (doi: 10.1017/jfm.2011.540)

Carver S, Sear D and Valentine E (1994) An observation of roll waves in a supraglacial meltwater channel, Harlech Gletscher, East Greenland. J. Glaciol., 40(134), 75-78

Dozier J (1974) Channel adjustments in supraglacial streams. Icefield Ranges Res. Proj. Sci. Results-Am. Geog. Soc., 4, 198205

Dozier J (1976) An examination of the variance minimization tendencies of a supraglacial stream. J. Hydrol., 31, 359-380

Ferguson RI (1973) Sinuosity of supraglacial streams. Bull. Geol. Soc. Am., 84, 251-256 (doi: 10.1130/0016-7606(1973)84<251: SOSS $>2.0 . \mathrm{CO} ; 2)$

Gulley J, Benn D, Screaton E and Martin J (2009) Mechanisms of englacial conduit formation and their implications for subglacial recharge. Quat. Sci. Rev., 28(19-20), 1984-1999

Hambrey MJ (1977) Supraglacial drainage and its relationship to structure, with particular reference to Charles Rabots Bre, Okstindan, Norway. Geogr. Tidsskr. - Nor. J. Geogr., 31(2), 69-77 (doi: 10.1080/00291957708545319)

Irvine-Fynn TDL, Hodson AJ, Moorman BJ, Vatne G and Hubbard AL (2011) Polythermal glacier hydrology: a review. Rev. Geophys., 49(RG4002), 1-37 (doi: 10.1029/2010RG000350)

Isenko E, Naruse R and Mavlyudov B (2005) Water temperature in englacial and supraglacial channels: change along the flow and contribution to ice melting on the channel wall. Cold Reg. Sci. Technol., 42, 53-62 (doi: 10.1016/j.coldregions.2004.12. 003)

Jarosch AH and Gudmundsson MT (2012) A numerical model for meltwater channel evolution in glaciers. Cryosphere, 6, 493503 (doi: 10.5194/tc-6-493-2012)

Karlstrom L, Gajjar P and Manga M (2013) Meander formation in supraglacial streams. J. Geophys. Res., 118, 1897-1907 (doi: 10.1002/jgrf.20135,2013)

Karlstrom L, Zok A and Manga M (2014) Near-surface permeability in a supraglacial drainage basin on the Llewellyn Glacier, Juneau Icefield, British Columbia. Cryosphere, 8, 537-546 (doi: 10.5194/tc-8-537-2014)

Knighton AD (1972) Meandering habit of supraglacial streams. Geol. Soc. Am. Bull., 83, 201-204

Knighton AD (1981) Channel form and flow characteristics of supraglacial streams, Austre Okstindbreen, Norway. Arct. Alp. Res., 13 (3), 295-306

Knighton AD (1998) Fluvial forms and processes: a new perspective. Arnold, London

Lampkin DJ and Vanderberg J (2014) Supraglacial melt channel networks in the Jakobshavn Isbrae region during the 2007 melt season. Hydrol. Process, 28, 6038-6053 (doi: 10.1002/ hyp.10085) 
Marston RA (1983) Supraglacial stream dynamics on the Juneau icefield. Ann. Assoc. Am. Geogr., 73(4), 597-608

Moorman BJ and Michel FA (2000) Glacial hydrological system characterization using ground-penetrating radar. Hydrol. Process, 14, 2645-2667

Smith LC and 5 others (2015) Efficient meltwater drainage through supraglacial streams and rivers on the southwest Greenland ice sheet. PNAS, 112(4), 1001-1006 (doi: 10.1073/pnas.1413024112)

Sole A and 6 others (2013) Winter motion mediates dynamic response of the Greenland ice sheet to warmer summers. Geophys. Res. Lett., 40, 3940-3944 (doi: 10.1002/grl.50764)

Van der Meer JJM (2004) Spitsbergen push moraines. Elsevier Science, Amsterdam

Vatne G and Refsnes I (2003) Channel pattern and geometry of englacial conduits. In Eraso A and Dominguez C eds. 6th
International Symposium on Glacier Caves and Karst in Polar Regions. Madrid, International Commission on Glacier Caves and Karst in Polar Regions, Ny-Ålesund, Svalbard, Norway, 181-188

Wainstein P, Moorman B and Whitehead K (2014) Glacial conditions that contribute to the regeneration of Fountain Glacier proglacial icing, Bylot Island, Canada. Hydrol. Process, 28, 2749-2760 (doi: 10.1002/hyp.9787)

Whitehead K, Moorman BJ and Hugenholtz CH (2013) Brief communication: low-cost, on-demand aerial photogrammetry for glaciological measurement. Cryosphere, 7, 1879-1884 (doi: 10.5194/tc-7-1879-2013)

Willis IC, Arnold NS and Brock BW (2002) Effect of snowpack removal on energy balance, melt and runoff in a small supraglacial catchment. Hydrol. Process, 16, 2721-2749 (doi: 10.1002/ hyp.1067) 